\title{
Synthesis of 2-Amino-4-pyrimidinones from Resin-bound Guanidines Prepared \\ Using Bis-(allyloxycarbonyl)-protected Triflylguanidine
}

Christoph W. Zapf and Murray Goodman

\section{Supplemental Material}

\section{Table of Content}

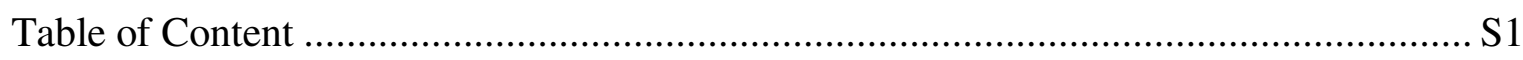

General Experimental Information ................................................................. 2

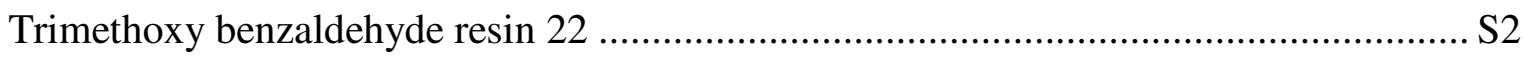

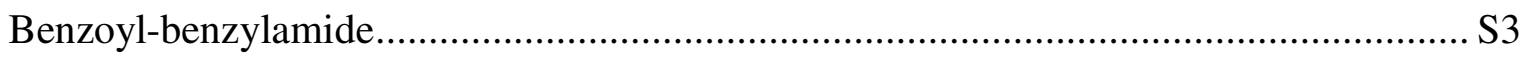

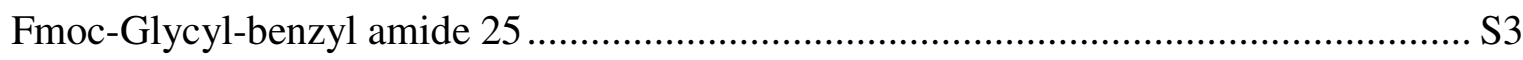

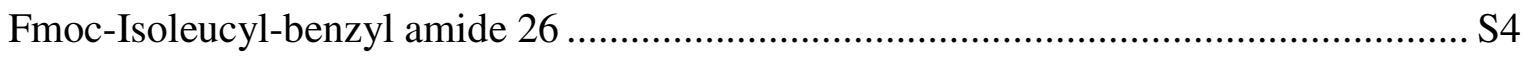

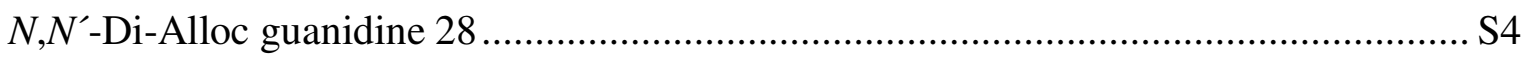

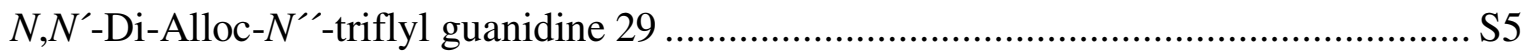

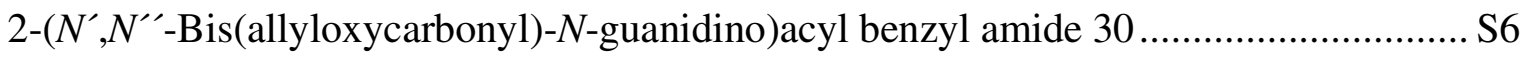

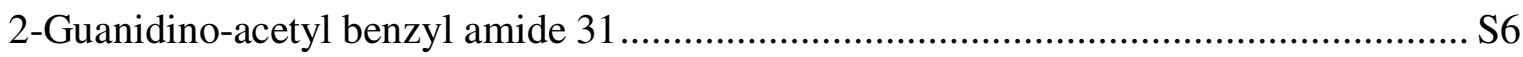

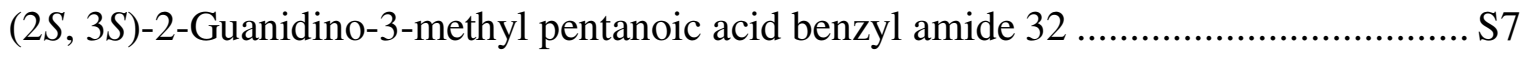

$N$-Benzyl-2-(4-methyl-6-oxo-1,6-dihydro-pyrimidin-2ylamino)-acetamide 33 .............. S7

$N$-Benzyl-2-(4,5-dimethyl-6-oxo-1,6-dihydro-pyrimidin-2ylamino)-acetamide 34......... S7

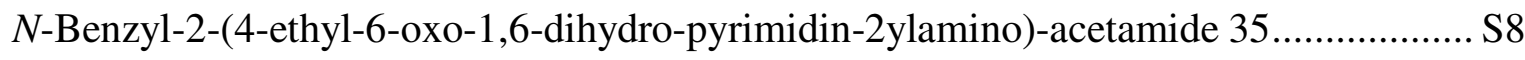

(S)-2-(4-Ethyl-6-oxo-1,6-dihydro-pyrimidin-2ylamino)-(S)-3-methyl-pentanoic

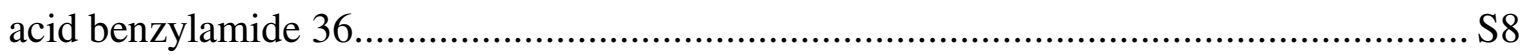


General Experimental Information: Reactions in solution were monitored by thin-layer chromatography (TLC) carried out on $0.25 \mathrm{~mm}$ E. Merck silica gel plates (60F254) using UV light as the visualization agent. The N-H containing compounds were visualized by exposing the TLC plates to chlorine gas (freshly generated by concentrated hydrochloric acid and potassium permanganate) for approximately 30-60 seconds. Subsequently, the TLC plates were dipped into a solution prepared by combining an aqueous $\mathrm{KI}\left(500 \mathrm{mg} \mathrm{KI}\right.$ in $50 \mathrm{~mL} \mathrm{H}_{2} \mathrm{O}$ ) and an aqueous o-tolidine (500 mg o-tolidine in $45 \mathrm{~mL} \mathrm{H}_{2} \mathrm{O}$ and $8 \mathrm{~mL}$ acetic acid) solution. Alternatively, TLC plates were visualized utilizing a $2 \%$ ninhydrin solution in ethanol.

The NMR spectra were obtained on a $400 \mathrm{MHz}$ spectrometer. Chemical shifts $(\delta)$ are reported in parts per million ( $\mathrm{ppm}$ ) relative to residual undeuterated solvent as an internal standard. The following abbreviations were used to explain the multiplicities: $\mathrm{s}=$ singlet, $\mathrm{d}=$ doublet, $\mathrm{t}=$ triplet, $\mathrm{q}=$ quartet, $\mathrm{dd}=$ doublet of doublets, $\mathrm{dt}=$ doublet of triplets, $\mathrm{m}=$ multiplet.

Mass spectra were obtained using electrospray and MALDI-FTMS techniques.

For analytical RP-HPLC, the flow rate was set to $1.0 \mathrm{~mL} / \mathrm{min}$, using an analytical $\mathrm{C}_{18}$ column ( $25 \times 0.46 \mathrm{~cm}, 5$ microns, $\left.300 \AA\right)$. Solvents used were as follows: solvent A $0.1 \% \mathrm{TFA} / \mathrm{H}_{2} \mathrm{O}$; solvent $\mathrm{B}-0.1 \% \mathrm{TFA} / \mathrm{CH}_{3} \mathrm{CN}$. Analysis of compounds by RP-HPLC was carried out utilizing a gradient condition (solvent A 90-10\% over 30 min).

Trimethoxy benzaldehyde resin 22: Tentagel resin 25 (1 g, $0.46 \mathrm{mmol})$ was placed in a pear-shaped 3-neck flask equipped with a thermometer under argon to which 2,6-dimethoxy-4-hydroxy benzaldehyde 26 (167 mg, 0.92 mmol, 2 eq.) in $N$-methyl pyrrolidinone $(6 \mathrm{~mL})$ was added. The suspension was immersed in an oil bath set to $50^{\circ} \mathrm{C}$ 
for $10 \mathrm{~min}$ before $\mathrm{Cs}_{2} \mathrm{CO}_{3}(450 \mathrm{mg}, 1.38 \mathrm{mmol}, 3 \mathrm{eq}$.) was added in several portions. After $24 \mathrm{~h}$ the resin was filtered and washed alternating DMF and methanol followed by methylene chloride and methanol after which the resin was dried in a desiccator.

Benzoyl-benzylamide: In a typical solid-phase reaction vessel, trimethoxy benzaldehyde resin $22(1 \mathrm{~g}, 0.43 \mathrm{mmol})$ was allowed to react with benzylamine in the presence of sodium triacetoxyborohydride $(1.06 \mathrm{~g}, 2.15 \mathrm{mmol}, 5$ eq.) in $10 \mathrm{~mL} 1 \%$ acetic acid in DMF for 4h. An analytical sample of the thus obtained dibenzylamine resin $\mathbf{2 7}$ (63 mg, $0.026 \mathrm{mmol}$ ) was allowed to react with benzoyl chloride $(60 \mu \mathrm{L}, 0.52 \mathrm{mmol}$, 20 eq.) in the presence of triethylamine ( $72 \mu \mathrm{L}, 0.52 \mathrm{mmol}, 20$ eq.) in DMF $(1 \mathrm{~mL})$ for 3h. The resin was washed thoroughly, alternating DMF and methanol followed by methylene chloride and methanol, after which the target compound was cleaved from the resin utilizing 50\% (v/v) TFA/C $\mathrm{CH}_{2} \mathrm{Cl}_{2} .{ }^{1} \mathrm{H}-\mathrm{NMR}$ (DMSO- $\left.d_{6}, 400 \mathrm{MHz}, \delta\right) 9.02(\mathrm{t}, 1 \mathrm{H}$, 8Hz), 7.90-7.87 (m, 2H), 7.53-7.44 (m, 3H), 7.32-7.30 (m, 4H), 7.29-7.20 (m, 1H), 4.47 (d, 2H, 8Hz). MS (ESI) $234[\mathrm{M}+\mathrm{Na}]^{+}, 250[\mathrm{M}+\mathrm{K}]^{+}, 445\left[\mathrm{M}_{2}+\mathrm{Na}\right]^{+}, 210[\mathrm{M}-\mathrm{H}]^{-}, 246$ $[\mathrm{M}+\mathrm{Cl}]^{-}, 324[\mathrm{M}+\mathrm{TFA}]^{-}$. Analytical RP-HPLC $\mathrm{R}_{\mathrm{t}}=28.31 \mathrm{~min}$.

Fmoc-Glycyl-benzyl amide 25: Dibenzylamine resin 24 (400 mg, 0.18 mmol) was allowed to react with Fmoc-Gly-OH (273 mg, $0.92 \mathrm{mmol}, 5$ eq.) in the presence of HOAt (125 mg, $0.92 \mathrm{mmol}, 5$ eq.), HATU (350 mg, $0.92 \mathrm{mmol}, 5$ eq.) and triethylamine (128 $\mu \mathrm{L}, 0.92 \mathrm{mmol}, 5$ eq.) for $19 \mathrm{~h}$. The resin was washed thoroughly, alternating DMF and methanol followed by methylene chloride and methanol. An aliquot of resin was allowed to react with benzoyl chloride $(60 \mu \mathrm{L}, 0.52 \mathrm{mmol}, 20$ eq.) in the presence of triethylamine ( $72 \mu \mathrm{L}, 0.52 \mathrm{mmol}, 20$ eq.) in DMF $(1 \mathrm{~mL})$ for $2 \mathrm{~h}$. The resin was washed thoroughly, alternating DMF and methanol followed by methylene chloride and 
methanol, after which the target compound was cleaved from the resin with neat TFA. ${ }^{1} \mathrm{H}-\mathrm{NMR}\left(\mathrm{DMSO}-d_{6}, 400 \mathrm{MHz}, \delta\right) 8.34$ (t, 1H, 11.6Hz), 7.89 (d, 2H, 7.6Hz), 7.72 (d, 2H, 7.6Hz), $7.55(\mathrm{t}, 1 \mathrm{H}, 5.8 \mathrm{~Hz}), 7.42(\mathrm{t}, 2 \mathrm{H}, 7.4 \mathrm{~Hz}), 7.36-7.21(\mathrm{~m}, 7 \mathrm{H}), 4.30-4.21(\mathrm{~m}, 5 \mathrm{H})$, $3.65(\mathrm{~d}, 2 \mathrm{H}, 6.8 \mathrm{~Hz})$. MS (ESI) $387[\mathrm{M}+\mathrm{H}]^{+}, 409[\mathrm{M}+\mathrm{Na}]^{+}, 385[\mathrm{M}-\mathrm{H}]^{-}, 421[\mathrm{M}+\mathrm{Cl}]^{-}$. Analytical RP-HPLC $\mathrm{R}_{\mathrm{t}}=24.18 \mathrm{~min}$.

Fmoc-Isoleucyl-benzyl amide 26: Dibenzylamine resin 24 (70 mg, $30 \mu \mathrm{mol})$ was suspended in DMF (2 mL) allowed to react with Fmoc-Ile-OH (32 mg, $90 \mu \mathrm{mol}, 3$ eq.) in the presence of DIC (23 $\mu \mathrm{L}, 150 \mu \mathrm{mol}, 5$ eq.), HOBt $(20 \mathrm{mg}, 150 \mu \mathrm{mol}, 5$ eq.) and triethylamine $(21 \mu \mathrm{L}, 150 \mu \mathrm{mol}, 5$ eq.) for $19 \mathrm{~h}$. The resin was washed thoroughly, alternating DMF and methanol followed by methylene chloride and methanol, after which the target compound was cleaved from the resin for $2 \mathrm{~h}$ utilizing neat TFA.

${ }^{1} \mathrm{H}-\mathrm{NMR}\left(\mathrm{DMSO}-d_{6}, 400 \mathrm{MHz}, \delta\right) 8.47$ (t, 1H, 11.2Hz), $7.88(\mathrm{~d}, 2 \mathrm{H}, 7.6 \mathrm{~Hz}), 7.74$ (dd, 2H, 3.4Hz, 7.4Hz), 7.47 (d, 1H, 8.8Hz), $7.41(\mathrm{t}, 2 \mathrm{H}, 7.6 \mathrm{~Hz}), 7.32-7.18(\mathrm{~m}, 7 \mathrm{H}), 4.28-$ $4.20(\mathrm{~m}, 5 \mathrm{H}), 3.90-3.86(\mathrm{~m}, 1 \mathrm{H}), 1.76-1.71(\mathrm{~m}, 1 \mathrm{H}), 1.46-1.40(\mathrm{~m}, 1 \mathrm{H}), 1.15-1.08(\mathrm{~m}$, 1H), 0.82-0.79 (m, 6H). Analytical RP-HPLC $\mathrm{R}_{\mathrm{t}}=27.84 \mathrm{~min}$.

$\boldsymbol{N}, \boldsymbol{N}^{\prime}$-Di-Alloc guanidine 28: In a $250 \mathrm{~mL}$ round bottom flask guanidine hydrochloride 27 (2.87 g, $30 \mathrm{mmol})$ and benzyltriethylammonium chloride (137 mg, $0.6 \mathrm{mmol}, 0.02$ eq.) was dissolved in aqueous $\mathrm{NaOH}(20 \mathrm{~mL}, 6 \mathrm{~N})$ and methylene chloride $(60 \mathrm{~mL})$. The solution was cooled to $0^{\circ} \mathrm{C}$ in an ice bath for $15 \mathrm{~min}$. Allyl chloroformate $(12.73 \mathrm{~mL}, 120 \mathrm{mmol}, 4$ eq.) was added quickly with vigorous stirring.

The reaction was allowed to proceed for 6h during which the initially clear twophase system became a white suspension. A white solid was removed by filtration which was identified as $N$-(allyloxycarbonyl) guanidine. The filtrate was diluted with $50 \mathrm{~mL}$ 
water and $50 \mathrm{~mL}$ DCM. The organic phase was collected and the aqueous extracted two additional times with $50 \mathrm{~mL}$ DCM. The combined organic phases were dried with $\mathrm{MgSO}_{4}$. The solvent was removed under reduced pressure and the oily residue purified by column chromatography. A solvent mixture of $5 \% \mathrm{Et}_{2} \mathrm{O}$ in $\mathrm{DCM}$ was chosen as the initial solvent condition to elute tri-Alloc guanidine $\left(\mathrm{R}_{\mathrm{f}}=0.59,10 \% \mathrm{Et}_{2} \mathrm{O}\right.$ in DCM). To elute the desired product from the column, the solvent mixture was changed to $50 \%$ $\mathrm{MeOH}$ in DCM. The compound was isolated as a white solid (4.50 g, 65.9\%). $\mathrm{R}_{\mathrm{f}}=0.27$ $\left(10 \% \mathrm{Et}_{2} \mathrm{O}\right.$ in DCM). ${ }^{1} \mathrm{H}-\mathrm{NMR}\left(\mathrm{CDCl}_{3}, 400 \mathrm{MHz}, \delta\right): 5.91(2 \mathrm{H}, \mathrm{ddt}, 5.8 \mathrm{~Hz}, 10.4 \mathrm{~Hz}$, 17.2Hz), $5.32(2 \mathrm{H}, \mathrm{dd}, 2 \mathrm{~Hz}, 17.2 \mathrm{~Hz}), 5.24(2 \mathrm{H}, \mathrm{dd}, 1 \mathrm{~Hz}, 10.6 \mathrm{~Hz}), 4.60(4 \mathrm{H}, \mathrm{d}, 5.6 \mathrm{~Hz})$. ${ }^{13} \mathrm{C}-\mathrm{NMR}\left(\mathrm{CDCl}_{3}, 100 \mathrm{MHz}, \delta\right): 159.0,131.8,118.1,66.3$. MS (ESI) $228[\mathrm{M}+\mathrm{H}]{ }^{+}, 250$ $[\mathrm{M}+\mathrm{Na}]^{+}, 226[\mathrm{M}-\mathrm{H}]^{-}, 262[\mathrm{M}+\mathrm{Cl}]^{-}$.

$N, N^{\prime}$-Di-Alloc- $N^{\prime \prime}$-triflyl guanidine 29: Thoroughly dried $N, N^{\prime}$-di-Alloc guanidine 28 (4.50 g, $19.78 \mathrm{mmol}$ ) was flushed extensively with argon and dissolved in freshly distilled methylene chloride $(70 \mathrm{~mL})$. The solution was cooled to $-78{ }^{\circ} \mathrm{C}$ in an isopropanol/dry ice bath. After cooling for $10 \mathrm{~min}$ freshly distilled triethylamine (4.14 mL, $29.67 \mathrm{mmol}, 1.5$ eq.) was added dropwise via syringe and cooled for another 10 min. Triflic anhydride (4.99 mL, $29.67 \mathrm{mmol}, 1.5$ eq.) was added dropwise over 15 min via a syringe and the reaction was allowed to warm to RT. The cooling bath reached RT after approximately $5 \mathrm{~h}$ and the reaction was allowed to proceed for an additional hour. The reaction mixture was transferred into a separatory funnel, diluted with $70 \mathrm{~mL} \mathrm{DCM}$ and extracted four times with $25 \mathrm{~mL} 1 \mathrm{~N} \mathrm{HCl}$. The organic phase was dried over $\mathrm{MgSO}_{4}$ and the solvent removed under reduced pressure. The brown, oily residue was purified by column chromatography utilizing DCM as eluent. The product 
was obtained as a clear oil $(5.22 \mathrm{~g}, 73.5 \%) .{ }^{1} \mathrm{H}-\mathrm{NMR}\left(\mathrm{CDCl}_{3}, 400 \mathrm{MHz}, \delta\right): 5.91(2 \mathrm{H}$, ddt, $6.0 \mathrm{~Hz}, 10.8 \mathrm{~Hz}, 17.0 \mathrm{~Hz}), 5.40(2 \mathrm{H}, \mathrm{dd}, 1.2 \mathrm{~Hz}, 17.2 \mathrm{~Hz}), 5.34(2 \mathrm{H}, \mathrm{dd}, 1.2 \mathrm{~Hz}, 10.8 \mathrm{~Hz})$ $4.72(4 \mathrm{H}, \mathrm{d}, 6 \mathrm{~Hz}) .{ }^{13} \mathrm{C}-\mathrm{NMR}\left(\mathrm{CDCl}_{3}, 100 \mathrm{MHz}, \delta\right): 150.7,149.8,129.9,120.5,119.0$ (q, 317Hz), 68.5. MS (ESI) $360[\mathrm{M}+\mathrm{H}]^{+}, 382[\mathrm{M}+\mathrm{Na}]^{+}, 398[\mathrm{M}+\mathrm{K}]^{+}, 358[\mathrm{M}-\mathrm{H}]^{-}$.

\section{2-( $N^{\prime}, N^{\prime \prime}$-Bis(allyloxycarbonyl)- $N$-guanidino)acyl benzyl amide 30 : After} deprotection of resin $\mathbf{2 5}$ and $\mathbf{2 6}$ utilizing 20\% piperidine in DMF, the benzyl amide resin was allowed to react with $N, N^{\prime}$-di-Alloc- $N^{\prime \prime}$-triflyl guanidine 29 (5 eq.) for 22h followed by thorough washing of the resin alternating methylene chloride and methanol. An analytical resin sample $(\mathrm{R}=\mathrm{H})$ was cleaved with neat TFA for $2 \mathrm{~h}$. ${ }^{1} \mathrm{H}-\mathrm{NMR}\left(\mathrm{CDCl}_{3}\right.$, $400 \mathrm{MHz}, \quad)$ 7.34-7.25 (m, 5H), 6.59 (t, 1H, 4.8Hz), 5.95-5.84 (m, 2H), 5.38-5.19 (m, $4 \mathrm{H}), 4.66(\mathrm{~d}, 2 \mathrm{H}, 6.0 \mathrm{~Hz}), 4.56(\mathrm{~d}, 2 \mathrm{H}, 6.0 \mathrm{~Hz}), 4.45(\mathrm{~d}, 2 \mathrm{H}, 5.6 \mathrm{~Hz}), 4.13(\mathrm{~s}, 2 \mathrm{H}) . \mathrm{MS}$ (ESI) $375[\mathrm{M}+\mathrm{H}]^{+}, 397[\mathrm{M}+\mathrm{Na}]^{+}, 413[\mathrm{M}+\mathrm{K}]^{+}$. Analytical RP-HPLC $\mathrm{R}_{\mathrm{t}}=22.28 \mathrm{~min}$.

2-Guanidino-acetyl benzyl amide 31: To remove the Alloc-protecting groups, resin $30(\mathrm{R}=\mathrm{H})(2 \mathrm{~g}, 0.82 \mathrm{mmol})$ was prewashed with freshly distilled $\mathrm{CH}_{2} \mathrm{Cl}_{2}$. Subsequently the resin was suspended in $20 \mathrm{~mL}$ freshly distilled $\mathrm{CH}_{2} \mathrm{Cl}_{2}$ to which phenylsilane ( $2 \mathrm{~mL}, 16.4 \mathrm{mmol}, 20 \mathrm{eq}$.) and tetrakis(triphenylphosphine) palladium(0) (95 mg, $82 \mu$ mol, 0.1 eq.) was added. After $3 \mathrm{~h}$, the resin was washed with $\mathrm{CH}_{2} \mathrm{Cl}_{2}$, methanol and aqueous $\mathrm{NaCN}$ until the resin beads became colorless. Excess cyanide was removed by washing the resin twice with water, followed by two washings with THF to remove residual water. The resin was further rinsed several time alternating methanol and methylene chloride. An analytical resin sample was cleaved with neat TFA for $2 \mathrm{~h}$. ${ }^{1} \mathrm{H}-\mathrm{NMR}\left(\mathrm{DMSO}-d_{6}, 400 \mathrm{MHz}, \delta\right) 8.62(\mathrm{t}, 1 \mathrm{H}, 5.8 \mathrm{~Hz}), 7.55$ (t, 1H, 5.8Hz), 7.34-7.22 (m, 
9H), $4.31(\mathrm{~d}, 2 \mathrm{H}, 6.0 \mathrm{~Hz}), 3.88(\mathrm{~d}, 2 \mathrm{H}, 5.6 \mathrm{~Hz}) . \mathrm{MS}(\mathrm{ESI}) 207[\mathrm{M}+\mathrm{H}]^{+}$. Analytical RP-HPLC $\mathrm{R}_{\mathrm{t}}=14.74 \mathrm{~min}$.

(2S, 3S)-2-Guanidino-3-methyl pentanoic acid benzyl amide 32: This compound was prepared in an analogous fashion as carried out for 2-guanidino-acetyl benzyl amide 31. An analytical resin sample was cleaved with neat TFA for $2 \mathrm{~h} .{ }^{1} \mathrm{H}-\mathrm{NMR}$ (DMSO-d $\left.d_{6} 400 \mathrm{MHz}, \delta\right) 8.63(\mathrm{t}, 1 \mathrm{H}, 5.8 \mathrm{~Hz}), 7.68(\mathrm{~d}, 1 \mathrm{H}, 9.6 \mathrm{~Hz}), 7.60-6.90(\mathrm{~m}, 9 \mathrm{H})$, $4.31(\mathrm{~m}, 2 \mathrm{H}), 4.00(\mathrm{dd}, 1 \mathrm{H}, 6.8 \mathrm{~Hz}, 9.6 \mathrm{~Hz}), 1.85(\mathrm{~m}, 1 \mathrm{H}), 1.41-1.35(\mathrm{~m}, 1 \mathrm{H}), 1.11-1.03$ (m, 1H), 0.87-0.80 (m, 6H). MS (ESI) $263[\mathrm{M}+\mathrm{H}]^{+}$. Analytical RP-HPLC $\mathrm{R}_{\mathrm{t}}=22.94 \mathrm{~min}$.

N-Benzyl-2-(4-methyl-6-oxo-1,6-dihydro-pyrimidin-2ylamino)-acetamide 33: To resin-bound guanidine 31 (91 mg, $35 \mu \mathrm{mol})$ suspended in $\mathrm{MeOH}(2 \mathrm{~mL})$ was added 6N $\mathrm{NaOMe}$ (58 $\mu \mathrm{L}, 0.35 \mathrm{mmol}, 10$ eq.) and ethyl acetoacetate (44 $\mu \mathrm{l}, 0.35 \mathrm{mmol}, 10$ eq.). The reaction vessel was shaken for $22 \mathrm{~h}$ followed by thorough washing of the resin, alternating methanol and methylene chloride. The resin was dried in a desiccator and cleaved with $2 \mathrm{~mL}$ neat TFA for $2 \mathrm{~h}$. After the cleavage solution was collected, the resin was rinsed with methanol and the combined solutions were taken to dryness. Based on the initial loading the heterocycle was obtained in quantitative yield. ${ }^{1} \mathrm{H}-\mathrm{NMR}$ (DMSO$\left.d_{6}, 400 \mathrm{MHz}, \delta\right) 8.56(\mathrm{t}, 1 \mathrm{H}, 5.8 \mathrm{~Hz}), 7.34-7.21(\mathrm{~m}, 6 \mathrm{H}), 4.31(\mathrm{~d}, 2 \mathrm{H}, 6.0 \mathrm{~Hz}), 3.98(\mathrm{~d}, 2 \mathrm{H}$, $4.4 \mathrm{~Hz}), 2.07(\mathrm{~s}, 3 \mathrm{H})$. MS (ESI) $273[\mathrm{M}+\mathrm{H}]^{+}, 295[\mathrm{M}+\mathrm{Na}]^{+}$. Analytical RP-HPLC R $\mathrm{t}_{\mathrm{t}}=$ $18.05 \min$.

\section{$N$-Benzyl-2-(4,5-dimethyl-6-oxo-1,6-dihydro-pyrimidin-2ylamino)-acetamide}

34: To resin-bound guanidine 31 (67 mg, $26 \mu \mathrm{mol})$ suspended in $\mathrm{MeOH}(2 \mathrm{~mL})$ was added $6 \mathrm{~N}$ NaOMe (44 $\mu \mathrm{L}, 0.26 \mathrm{mmol}, 10$ eq.) and ethyl 2-methylacetoacetate (37 $\mu \mathrm{l}$, $0.26 \mathrm{mmol}, 10$ eq.). The reaction vessel was shaken for $21 \mathrm{~h}$ followed by thorough 
washing of the resin, alternating methanol and methylene chloride. The resin was dried in a desiccator and cleaved with $2 \mathrm{~mL}$ neat TFA for $2 \mathrm{~h}$. After the cleavage solution was collected, the resin was rinsed with methanol and the combined solutions were taken to dryness. ${ }^{1} \mathrm{H}-\mathrm{NMR}$ (DMSO- $\left.d_{6}, 400 \mathrm{MHz}, \delta\right) 8.63(\mathrm{t}, 1 \mathrm{H}, 5.6 \mathrm{~Hz}), 7.35-7.22(\mathrm{~m}, 5 \mathrm{H}), 4.31$ (d, 2H, 5.6Hz), $4.06(\mathrm{~d}, 5.2 \mathrm{~Hz}), 2.19(\mathrm{~s}), 1.82(\mathrm{~s}) . \mathrm{MS}(\mathrm{ESI}) 287[\mathrm{M}+\mathrm{H}]^{+}, 309[\mathrm{M}+\mathrm{Na}]^{+}$, $285[\mathrm{M}-\mathrm{H}]^{-}, 321[\mathrm{M}+\mathrm{Cl}]^{-}$. Analytical RP-HPLC $\mathrm{R}_{\mathrm{t}}=14.08 \mathrm{~min}$.

$N$-Benzyl-2-(4-ethyl-6-oxo-1,6-dihydro-pyrimidin-2ylamino)-acetamide 35: To resin-bound guanidine 31 (97 mg, $38 \mu \mathrm{mol})$ suspended in $\mathrm{MeOH}(2 \mathrm{~mL})$ was added $6 \mathrm{~N}$ $\mathrm{NaOMe}(63 \mu \mathrm{L}, 0.38 \mathrm{mmol}, 10$ eq.) and ethyl propionylacetate ( $48 \mu \mathrm{l}, 0.38 \mathrm{mmol}, 10$ eq.). The reaction vessel was agitated for $21 \mathrm{~h}$ followed by thorough washing of the resin, alternating methanol and methylene chloride. The resin was dried in a desiccator and cleaved with $2 \mathrm{~mL}$ neat TFA for $2 \mathrm{~h}$. After the cleavage solution was collected, the resin was rinsed with methanol and the combined solutions to dryness. ${ }^{1} \mathrm{H}-\mathrm{NMR}$ (DMSO- $d_{6}$, $400 \mathrm{MHz}, \delta) 8.58(\mathrm{t}, 1 \mathrm{H}, 5.8 \mathrm{~Hz}), 7.43-7.20(\mathrm{~m}, 6 \mathrm{H}), 4.30(\mathrm{~d}, 2 \mathrm{H}, 5.6 \mathrm{~Hz}), 3.99(\mathrm{~s}, 2 \mathrm{H})$, $2.35(\mathrm{~s}, 2 \mathrm{H}), 1.10(\mathrm{t}, 3 \mathrm{H}, 7.2 \mathrm{~Hz})$. MS (ESI) $287[\mathrm{M}+\mathrm{H}]^{+}, 309[\mathrm{M}+\mathrm{Na}]^{+}, 285[\mathrm{M}-\mathrm{H}]^{-}, 399$ [M+TFA]. HRMS $(\mathrm{m} / \mathrm{z})$ : $[\mathrm{M}+\mathrm{H}]^{+}$calcd for $\mathrm{C}_{15} \mathrm{H}_{19} \mathrm{~N}_{4} \mathrm{O}_{2}$ 287.1502, found 287.1505. Analytical RP-HPLC $\mathrm{R}_{\mathrm{t}}=12.97 \mathrm{~min}$.

(S)-2-(4-Ethyl-6-oxo-1,6-dihydro-pyrimidin-2ylamino)-(S)-3-methyl-pentanoic acid benzylamide 36: To resin-bound guanidine 32(130 mg, $52 \mu \mathrm{mol})$ suspended in $\mathrm{MeOH}(2 \mathrm{~mL})$ was added $6 \mathrm{~N} \mathrm{NaOMe}(87 \mu \mathrm{L}, 0.52 \mathrm{mmol}, 10$ eq.) and ethyl propionylacetate $(65 \mu \mathrm{l}, 0.52 \mathrm{mmol}, 10 \mathrm{eq}$.). The reaction vessel was shaken for $24 \mathrm{~h}$ followed by thorough washing of the resin, alternating methanol and methylene chloride. The resin was dried in a desiccator and cleaved with $2 \mathrm{~mL}$ neat TFA for $2 \mathrm{~h}$. After the 
cleavage solution was collected, the resin was rinsed with methanol and the combined solutions were taken to dryness. ${ }^{1} \mathrm{H}-\mathrm{NMR}$ (DMSO- $\left.d_{6}, 400 \mathrm{MHz}, \delta\right) 8.66(\mathrm{t}, 1 \mathrm{H}, 5.6 \mathrm{~Hz})$, 7.32-7.19 (m, 6H), $4.43(\mathrm{~m}, 1 \mathrm{H}), 4.30(\mathrm{t}, 2 \mathrm{H}, 6.2 \mathrm{~Hz}), 2.30(\mathrm{~m}, 2 \mathrm{H}), 1.83(\mathrm{~m}, 1 \mathrm{H}), 1.44$ $(\mathrm{m}, 1 \mathrm{H}), 1.09(\mathrm{~m}, 4 \mathrm{H}), 0.87(\mathrm{~m}, 6 \mathrm{H}) . \mathrm{MS}(\mathrm{ESI}) 343[\mathrm{M}+\mathrm{H}]^{+}, 365[\mathrm{M}+\mathrm{Na}]^{+}, 341[\mathrm{M}-\mathrm{H}]^{-}$, $377[\mathrm{M}+\mathrm{Cl}]^{-}$. Analytical RP-HPLC R $\mathrm{t}_{\mathrm{t}}=26.54 \mathrm{~min}$. 